ЕРЕМЕНКО Юлия Александровна - кандидат экономических наук, доцент кафедры маркетинга, торгового и таможенного дела Института экономики и управления - структурного подразделения Крымского федерального университета им. В.И. Вернадского» (295015, Россия, Республика Крым, 2. Симферополь, ул. Севастопольская, 21/4; jul_eremenko@mail.ru)

ЧЕНЦОВА Анна Владимировна - студентка 3-го курса Института экономики и управления структурного подразделения Крымского федерального университета им. В.И. Вернадского» (295015, Россия, Республика Крым, г. Симферополь, ул. Севастопольская, 21/4; annachensova15@gmail.com)

\title{
ОЦЕНКА ВЛИЯНИЯ ЭМОЦИОНАЛЬНОГО ВОСПРИЯТИЯ ВИЗУАЛЬНОГО КОНТЕНТА НА ПРИНЯТИЕ ПОЛИТИЧЕСКИХ РЕШЕНИЙ
}

\begin{abstract}
Аннотация. В работе проводится исследование особенностей эмоционального восприятия молодежью политического видеоконтента разных жанров: юмористического, видеомемов, выступлений политического лидера и видео, вызывающего отвращение. Проведенное психодиагностическое исследование с использованием адаптированной версии шкалы дифференциальных эмоций (DES) позволило оценить уровень эмоционального воздействия политического видеоконтента на молодежь, а также получить результаты влияния эмоций на их намерение принимать те или иные политические решения. Анализ данных показал, что просмотр юмористического видео и выступления политического лидера статистически значимо снизили индекс тревожно-депрессивных эмоций $(p=0,02, p=0,07$, где $p$ - критерий Вилкоксона) по сравнению с другими видеороликами. Оценка намерения поддержать политического лидера / законопроект была максимальной после просмотра видеовыступления политика $(2,9)$. Ключевые слова: политическая коммуникация, политический контент, молодежь, социальные сети, видеоролик, психодиагностические методы
\end{abstract}

Введение. Недавние революционные исследования в области изучения мозга позволили более глубоко понять природу принятия человеком различных решений, а также поменять взгляд на ряд основополагающих концепций в экономике и политике. Так, работа Д. Канемана, получившая Нобелевскую премию в 2002 г. за изучение формирования суждений и принятия решений в условиях неопределенности, способствовала переходу от устоявшейся парадигмы «размышление», «действие», «чувство» К эмоциональной революции - «чувство», «Действие», «размышление».

Понимание важности аффекта в принятии политических и экономических решений, с одной стороны, привело к обеспокоенности политических психологов и политологов тем, что политика становится все более эмоциональной, а избиратели отказываются от рациональности в пользу страсти ${ }^{1}$, а также тем, какое это оказывает влияние на существование основных демократических принципов. Так, Дэвис показывает, что быстрая реакция имеет приоритет перед взвешенными суждениями [Davies 2018]; Крауч, Клюгер и Рэчмен говорят, что люди больше доверяют своим эмоциям и чувствам, а не свидетельствам и фактам ${ }^{2}$ [Crouch 2017]. Такие ученые, как Хоггет, Томпсон, Прайер и ван Хоф

\footnotetext{
${ }^{1}$ Hewitt G. 2016. EU Referendum: Don't Discount Raw Emotion. - BBC News. 14 April. URL: https://www.bbc.co.uk/news/uk-politics-eu-referendum-36029874 (accessed 04.05.2021).

2 Kluger J. 2016. How Psychology Made the Brexit Vote Inevitable. - Time. 24 June. URL: https://time.com/4381837/brexit-psychology/ (accessed 04.05.2021); Rachman G. 2016. Trump and Brexit Feed off the Same Anger. - Financial Times. 1 August. URL: https://www.ft.com/content/dc8eb27a-57c3-11e6-9f70-badea1b336d4 (accessed 04.05.2021).
} 
впервые ввели понятие «эмоциональный поворот» [Hoggett, Thompson 2002; Prior, van Hoef 2018], который начался с нулевых годов.

С другой стороны, появилось множество научных исследований, пытающихся понять влияние различных эмоций на формирование суждений, оценок и политический выбор (см. табл. 1).

Таблица 1

Влияние эмоций на принятие политических решений

\begin{tabular}{|c|c|c|}
\hline Эмоция & Влияние & Автор \\
\hline Беспокойство & Побуждает искать новую информацию & \multirow{4}{*}{ [Marcus 2000] } \\
\hline Гнев & $\begin{array}{l}\text { Игнорирование новой информации } \\
\text { и формирование суждений на уже } \\
\text { имеющихся данных }\end{array}$ & \\
\hline Надежда и энтузиазм & $\begin{array}{l}\text { Вызывает более высокий уровень } \\
\text { интереса и участия в политике }\end{array}$ & \\
\hline Тревога и гнев & Влияют на политическую терпимость & \\
\hline Положительные эмоции & Оптимистическая оценка рисков & \multirow{2}{*}{$\begin{array}{l}\text { [Johnson, Tversky } \\
\text { 1983] }\end{array}$} \\
\hline Отрицательные эмоции & Пессимистическая оценка рисков & \\
\hline Энтузиазм & $\begin{array}{l}\text { Приводит к большей поляризации: } \\
\text { повышает лояльность сторонников и } \\
\text { отталкивает оппонентов }\end{array}$ & \multirow{2}{*}{ [Brader 2005] } \\
\hline Страх & $\begin{array}{l}\text { Стимулирует бдительность, приводит } \\
\text { к переоценке и восприимчивости к } \\
\text { рекламному контенту }\end{array}$ & \\
\hline Страх, дистресс & $\begin{array}{l}\text { Пессимистическая оценка риска, } \\
\text { не склонность к риску }\end{array}$ & \multirow{2}{*}{$\begin{array}{l}\text { [Lerner, Keltner } \\
\text { 2001] }\end{array}$} \\
\hline Гнев & $\begin{array}{l}\text { Оптимистическая оценка риска, } \\
\text { поиск риска }\end{array}$ & \\
\hline Отрицательные эмоции & Запоминание негативной информации & \multirow{2}{*}{ [Bower 1981] } \\
\hline Положительные эмоции & Запоминание позитивной информации & \\
\hline Грусть & $\begin{array}{l}\text { Повышает склонность восприятия } \\
\text { риска негативных событий }\end{array}$ & $\begin{array}{c}\text { [Hsee, Weber } \\
\text { 1997] }\end{array}$ \\
\hline Энтузиазм, гнев и страх & $\begin{array}{l}\text { Мобилизация политической } \\
\text { активности, вирусность }\end{array}$ & \multirow{2}{*}{$\begin{array}{l}\text { [Casas, Webb } \\
\text { Williams] }\end{array}$} \\
\hline Печаль & $\begin{array}{l}\text { Демобилизация политической } \\
\text { активности }\end{array}$ & \\
\hline Радость & $\begin{array}{l}\text { Повышает политическую активность, } \\
\text { снижает уровень беспокойства }\end{array}$ & $\begin{array}{l}\text { [Becker 2014; } \\
\text { Baumgartner, } \\
\text { Lockerbie 2018] }\end{array}$ \\
\hline
\end{tabular}

Таким образом, если ранее политологи противопоставляли аффективные сигналы (чувства) когнитивным сигналам (мыслям), то сейчас большее внимание уделяется взаимодействию между ними в понимании более целостной картины формирования политических суждений и мотивов принятия политических решений [Moss, Robinson, Watts 2020].

Недавние работы в области нейробиологии также указывают на существующий неразрывный синтез рационального и эмоционального в принятии реше- 
ний. Так, нейробиолог А. Дамасио в своем исследовании показал, что пациент с поврежденным отделом мозга, отвечающим за эмоции, утратил способность принятия решений. Ученый объясняет это существованием соматических маркеров - чувств, которые снабжены ярлыком и хранятся в нашем теле и подсознании. Именно эмоции позволяют людям маркировать вещи как хорошие, плохие или нейтральные, что важно при осуществлении выбора [Damasio 1999].

Методы оценки эмоций. С учетом важности эмоций и их влияния на восприятие окружающего мира, протекание когнитивных процессов и поведение достаточно много научных работ по психологии, физиологии было направлено на разработку точных методов их распознавания и идентификации. В теории и практике сложились два подхода к моделированию эмоций: дискретные и размерные модели. Первый подход основан на классификации эмоций, принятой в повседневной жизни, например радость, грусть, страх и др. Второй предполагает оценку валентности эмоций, то есть приятность/неприятность и их интенсивность с точки зрения их активации от низкого до высокого.

Ряд ученых считают недостаточным деление эмоций на положительные и отрицательные [Brader 2005, Lerner, Keltner 2001]. Большинство работ, приведенных в табл. 1, показывают, что разные эмоции одной и той же валентности по-разному влияют на суждения и принятие политических решений.

К наиболее распространенным методам психодиагностики эмоциональных состояний можно отнести метод дифференциальных эмоций $D E S$, опросник Ч. Спилбергера в модификации Ю.Л. Ханина (уровень тревожности личностной и ситуационной), опросник САН Ю. Доскина (самочувствие, активность, настроение), методика самооценки психических состояний по Г. Айзенку.

Наиболее объективными методами оценки эмоций считаются физиологические - использование электроэнцефалографии для измерения ответов центральной нервной системы на предъявление эмоциональных стимулов, оценивающей их валентность и интенсивность. Более широкий класс аффективных вычислений основан на получении ответов от вегетативной нервной системы. К данной группе методов можно отнести электроэнцефалографию (ЭЭГ), электромиограмму (ЭМГ), частоту дыхания, айтрекинг, кодирование лицевых движений. Также зарекомендовала себя методика оценки эндогенного счета времени по длительности индивидуальной минуты.

На основе обозначенных выше методик разрабатываются программы автоматического определения эмоций - аффективные вычисления, основанные на междисциплинарном подходе, включающие знания из области психологии, физиологии и искусственного интеллекта.

Далее предложим результаты исследования влияния политических видеороликов разных жанров на эмоциональное восприятие молодежи, а также их намерение поддержать политического лидера / законопроект.

Материалы и методы исследования. Для оценки эмоционального восприятия видеоконтента была использована адаптированная версия шкалы дифференциальных эмоций (Dissociative Experience Scale, DES, Izart et al. 1974). Опрос проводился до и после демонстрации политического видеоролика определенного жанра для каждой экспериментальной группы, что дало возможность наблюдать динамику изменения эмоциональной реакции испытуемых на предъявленный стимул, а также оценить намерение испытуемых поддержать политического лидера / законопроект. Выбранный психодиагностический метод допускает возможность динамично отслеживать психоэмоциональное состояние субъектов от исходного состояния и на выходе из смоделированной обстановки - после просмотра видеоконтента.

В соответствии с выбранной методикой исследовались 10 базовых эмоций: 
интерес, радость, удивление, горе, гнев, отвращение, презрение, страх, стыд, вина.

Индекс позитивных эмоций (ПЭМ) характеризует степень позитивного эмоционального отношения субъекта к наличной ситуации:

ПЭМ $=\sum 1,2,3$ (интерес + радость + удивление).

Индекс острых негативных эмоций (НЭМ) отражает общий уровень негативного эмоционального отношения субъекта к наличной ситуации:

НЭМ = $24,5,6,7$ (горе + гнев + отвращение + презрение).

Индекс тревожно-депрессивных эмоций (ТДЭМ) отражает уровень относительно устойчивых индивидуальных переживаний тревожно-депрессивного комплекса эмоций, опосредующих субъективное отношение к наличной ситуации:

ТДЭМ $=\sum 8,9,10$ (страх + стыд + вина $)$.

Дизайн и стимулы. Для достижения цели исследования были отобраны четыре политических видеоролика разных жанров (юмористический, видеомемы, видеовыступление политического лидера и видео, вызывающее отвращение). Длительность предъявления стимульного материала составляла 1,5-2 минуты.

Общая процедура. В начале эксперимента участники были ознакомлены с целями и задачами исследования, а также заполнили листы информационного согласия на обработку данных. С применением правил биоэтики были тестированы студенты обоего пола $(N=40)$, средний возраст $19,58 \pm 0,45$ лет. В зависимости от контента испытуемые были разделены на 4 экспериментальные группы: первая $\left(N_{1}=10\right)$, смотревшая юмористическое видео, вторая $\left(N_{2}=10\right)-$ видеомемы, третья $\left(N_{3}=10\right)-$ декларативное выступление политического лидера, четвертая $\left(N_{4}\right)$ - видео, вызывающее отвращение. Опрос проводился до и после демонстрации политического видео разного жанра, что дало возможность наблюдать динамику изменения эмоциональной реакции испытуемых на предъявленный стимул. После предъявления стимула участники-добровольцы ответили на вопрос о намерении поддержать политического лидера / партию по шкале (от 0 до 6), где 0 - абсолютно не поддерживаю, 6 - абсолютно поддерживаю.

оборудование. Анкеты были подготовлены в google-формах. Обработка стимульного материала осуществлялась с использованием Movavi Video Suite. Анализ полученных данных был проведен с использованием методов экономико-статистического анализа, реализованного в пакете программ SPSS 23.0.

Результаты исследования. Такой вид контента, как видео, способен вызвать достаточно сильные эмоции благодаря активизации аудиальной и визуальной сенсорных систем. Анализ изменений психологических реакций студентовдобровольцев при восприятии политического видеоконтента разных жанров выявил некоторые изменения в психоэмоциональном статусе участников эксперимента (см. табл. 2).

Из табл. 2 видно, что просмотр юмористического видео и видео выступления политического лидера привел к значимому снижению индекса тревожнодепрессивных эмоций. Полученные результаты согласуются с рядом научных исследований, которые указывают на способность юмора повысить политическую активность, а также снизить тревожность, напряженность [Becker 2014, Baumgartner, Lockerbie 2018]. Молодые люди очень восприимчивы к юмористическому контенту, что объясняется легкостью его восприятия и способностью вызвать положительные эмоции. Однако ученые утверждают, что юмор снижает контраргументацию или проверку аргументов [Nabi, Moyer-Guse, 
Таблица 2

Сравнительная характеристика эмоционального состояния (по результатам шкалы дифференциальных эмоций) испытуемых до и после просмотра политического видеоконтента

\begin{tabular}{|l|c|c|c|c|c|c|c|}
\hline \multirow{2}{*}{$\begin{array}{c}\text { Политический } \\
\text { видеоконтент }\end{array}$} & \multicolumn{3}{|c|}{ Исходные данные } & \multicolumn{3}{|c|}{ После эксперимента } & \multicolumn{2}{|c|}{$\begin{array}{c}\text { Оценка } \\
\text { намерения } \\
\text { поддержать } \\
\text { лидера/ } \\
\text { законопроект } \\
\text { (от 0 до 6 баллов) }\end{array}$} \\
\cline { 2 - 8 } & ПЭМ & НЭМ & ТДЭМ & ПЭМ & НЭМ & ТДЭМ \\
\hline $\begin{array}{l}\text { Юмористическое } \\
\text { видео }\end{array}$ & 23 & 18,6 & 16,2 & 26,2 & 19,6 & $12,3^{*}$ & 2,4 \\
\hline Видеомемы & 21,8 & 15,2 & 11,9 & 20,6 & 18,4 & 10,9 & - \\
\hline $\begin{array}{l}\text { Видеовыступление } \\
\text { Политического } \\
\text { лидера }\end{array}$ & 26,1 & 19,5 & 14,8 & 24,9 & 18,8 & $12,1^{* *}$ & 2,9 \\
\hline $\begin{array}{l}\text { Видео, вызывающее } \\
\text { отвращение }\end{array}$ & 23,6 & 18,7 & 14,9 & 23,7 & 30,4 & 19,8 & 2,3 \\
\hline
\end{tabular}

Примечание. ПЭМ - индекс позитивных эмоций, НЭМ - индекс острых негативных эмоций, ТДЭМ - индекс тревожно-депрессивных эмоций.

$* \mathrm{p}=0,02$ (критерий Вилкоксона)

$* * \mathrm{p}=0,027$ (критерий Вилкоксона)

Byrne 2007; Young 2008], что делает его успешной технологией манипуляции в политической коммуникации.

Снижение показателя тревожно-депрессивных эмоций после просмотра декларативного выступления политического лидера может говорить о доверчивости молодежи к обещаниям и убеждениям.

Результаты исследования также показали наивысший показатель оценки намерения поддержать политического лидера / законопроект после просмотра выступления политика, что может говорить о пользе рационального подхода в процессе осуществления политического выбора.

Вывод. Еще с древних времен такие философы, как Аристотель, Платон, Гоббс, Декарт, а также мыслители эпохи Просвещения Юм, Смит пытались понять и объяснить влияние эмоций на природу человека и его способности к политике. Результаты современных исследований позволяют достаточно глубоко понять влияние аффекта на формирование политических суждений, мнений и совершение политических действий. Эти знания сегодня активно используются в разработке стратегии политической коммуникации. Так, победу на президентских выборах 2019 г. в Украине одержал В.А. Зеленский, бывший комедийный актер, продюсер и сценарист. Именно такой образ кандидата в президенты способен был снизить уровень тревожно-депрессивных эмоций населения, а также уменьшить сушествующее негативное отношение и недоверие к политике.

Таким образом, с одной стороны, основная черта современных подходов больше не противопоставлять эмоции разуму, а, напротив, признать их неотъемлемой частью когнитивного процесса. Они важны для восприятия и оценивания, следовательно, без них невозможно и само суждение. С другой стороны, остается открытым вопрос этики и морали использования современных знаний об эмоциях в создании и применении манипулятивных технологий по продвижению политических лидеров и законопроектов, где население высту- 
пает не субъектом, адекватно воспринимающим и оценивающим информацию, а объектом коммуникативного процесса.

Исследование выполнено при финансовой поддержке РФФИ и ЭИСИ в рамках научного проекта № 20-011-33033.

\section{Список литературы}

Baumgartner J., Lockerbie B. 2018. Maybe it Is More Than a Joke: Satire, Mobilization, and Polical Participation. - Social Science Quarterly. Vol. 99. Is. 3. P. 1-15.

Becker A.B. 2014. Playing with Politics: Online Political Parody, Affinity for Political Humor, Anxiety Reduction, and Implications for Political Efficacy. - Mass Communication and Society. Vol. 17. Is. 3. P. 424-445.

Bower G. 1981. Mood and Memory. - American Psychologist. Vol. 36. P. 129-148.

Brader T. 2005. Striking a Responsive Chord: How Political Ads Motivate and Persuade Voters by Appealing to Emotions. - American Journal of Political Science. Vol. 49. Is. 2. P. 388-405.

Casas A., Webb Williams N. 2018. Images that Matter: Online Protests and the Mobilizing Role of Pictures. - Political Research Quarterly. Vol. 72. Is. 2. P. 360-375.

Crouch C. 2017. Balancing Reason and Emotion in Democracy. - British Academy Blog. 23 February. URL: https://www.thebritishacademy.ac.uk/blog/balancingreason-and-emotion-democracy (accessed 04.05.2021).

Damasio A. 1999. The Feeling of What Happens: Body and Emotion in the Making of Consciousness. Harcourt College Publishers. 386 p.

Davies W. 2018. Nervous States: How Feeling Took Over the World. London: Penguin. $272 \mathrm{p}$.

Hoggett P., Thompson S. 2002. Toward a Democracy of the Emotions. Constellations. Vol. 9. Is. 1. P. 106-126.

Hsee C., Weber E. 1997. A Fundamental Prediction Error: Self-other Discrepancies in Risk Reference. - Journal of Experimental Psychology. Vol. 126. P. 45-53.

Johnson E., Tversky A. 1983. Affect, Generalization, and the Perception of Risk. Journal of Personality and Social Psychology. Vol. 45. Is. 1. P. 20-31.

Lerner J., Keltner D. 2001. Fear, Anger, and Risk. - Journal of Personality and Social Psychology. Vol. 81. P. 146-159.

Marcus G.E. 2000. Emotions in Politics. - Annual Review of Political Science. Vol. 3. P. 221-250.

Moss J., Robinson E., Watts J. 2020. Brexit and the Everyday Politics of Emotion: Methodological Lessons from History. - Political Studies. Vol. 68. Is. 4. P. 837-856.

Nabi R.L., Moyer-Guse E., Byrne S. 2007. All Joking Aside: A Serious Investigation into the Persuasive Effect of Funny Social Issue Messages. - Communication Monographs. Vol. 74. P. 29-54.

Prior A., van Hoef Y. 2018. Interdisciplinary Approaches to Emotions in Politics and International Relations. - Politics and Governance. Vol. 6. Is. 4. P. 48-52.

Young D.G. 2008. The Privileged Role of the Late-Night Joke: Exploring Humor's Role in Disrupting Argument Scrutiny. - Media Psychology. Vol. 11. P. 119-142. 
EREMENKO Yulia Aleksandrovna, Cand.Sci. (Econ.), Associate Professor of the Chair of Marketing, Trade and Customs Affairs (Academic Unit) of Vernadsky Crimean Federal University (21/4 Sevastopolskaya St, Simferopol, Republic of Crimea, Russia,295015; email:jul_eremenko@mail.ru)

CHENTSOVA Anna Vladimirovna, $3^{\text {rd }}$ year student at the Institute of Economics and Management (Academic Unit) of Vernadsky Crimean Federal University (21/4 Sevastopolskaya St, Simferopol, Republic of Crimea, Russia, 295015; annachensova15@gmail.com)

\section{ASSESSMENT OF THE INFLUENCE OF EMOTIONAL PERCEPTION OF VISUAL CONTENT ON POLITICAL DECISION-MAKING}

Abstract. The paper investigates the peculiarities of the emotional perception of political video content of different genres: humorous, video memes, the speech of a political leader and a video that causes disgust, by the youth. The conducted psycho-diagnostic research, using an adapted version of the scale of differential emotions (DES), made it possible to assess the level of emotional impact of political video content on young people, as well as to obtain the results of the influence of emotions on their intention to make certain political decisions.

Analysis of the data showed that watching a humorous video and speaking of a political leader statistically significantly reduced the index of anxious-depressive emotions ( $p=0.02, p=0.07$ - Wilcoxon test), compared with other videos. The assessment of the intention to support a political leader/bill was the highest after watching the video of the politician's speech (2.9).

Keywords: political communication, political content, youth, social networks, video, psycho-diagnostic methods 